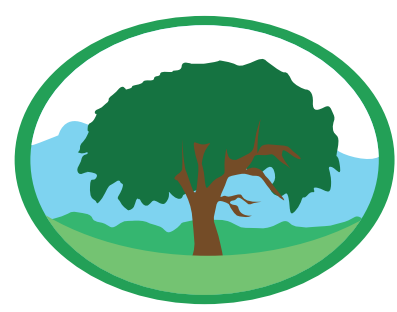

\title{
Cinética e equilíbrio secular das principais séries radioativas e suas implicações ambientais
}

WILLIAN CÉZAR NADALETI, PAULO BELLI FILHO, KASSEM KALIFE NEGE, ROBSON ANDREAZZA, MAURIZIO QUADRO, ERICO KUNDE CORREA, LUCIARA CORREA, DIULIANA LEANDRO, BRUNO VIEIRA, ANDRÉA CASTRO.

Palavras-chave: radioatividade, urânio, radônio.

\section{Resumo}

A população está continuamente sujeita aos problemas causados pela radiação, o contato com materiais naturalmente radioativos é diário. Essa exposição prolongada pode causar sérios problemas à saúde.Nesse sentido, esse trabalho faz uma revisão da literatura sobre as principais formas de radiação a que a humanidade está submetida, abordando o decaimento radioativo dos principais elementos como urânio, tório e rádio. Foi realizada uma revisão sobre as principais ações de prevenção à radiação, e por fimfoi proposta uma transposição didática sobre o ensino de física moderna, tendo como foco a utilização de objetos educacionais dentro da sala de aula.

\section{Kinetics and secular equilibrium of the main radioactive series and its environmental implications}

Key-words: radioactivity, uranium, radom.

\begin{abstract}
The population is continuously subject to the problems caused by radiation, one sees that the contact with naturally radioactive materials is daily. This prolonged exposure can cause serious problems to health. In this sense, this work is a literature review of the main forms of radiation to which mankind is subjected, addressing the radioactive decay of the main elements such as uranium, thorium, and radium. A review of the main actions to radiationwas performed, and finally it was proposed a didactic transposition of the modern physical education, focusing on the use of educational materials in the classroom.
\end{abstract}




\section{INTRODUÇÃO}

O ser humano está continuamente exposto a radiações ionizantes de materiais naturalmente radioativos. A origem destes materiais é a crosta terrestre, mas são encontrados em materiais de construção, ar, água, alimentos e no corpo humano. Em todo o mundo, materiais de construção contendo materiais radioativos têm sido usados por geraçóes. Como os indivíduos permanecem mais de $80 \%$ do tempo em locais fechados, as radiaçôes destes locais provocam situaçóes de exposiçóes prolongadas (ICRU, 1998).

No século XVI, o adoecimento de trabalhadores de minas foi observado e anos depois diagnosticado como câncer de pulmão. A constatação de que as altas taxas de câncer em mineiros estavam relacionadas com a presença de elementos radioativos como o Radônio ${ }^{222} \mathrm{Rn}$ ) e seus produtos de decaimento, deuse no início dos anos 50. Dessa forma, iniciou-se uma preocupação crescente relacionada com as doses deste tipo de radiação a que as pessoas estão sujeitas (NAZAROFF; NERO JR, 1988).

Os radionuclídeos provenientes das séries do urânio e do tório contribuem com cerca de $70 \%$ da dose anual por pessoa devido à exposição à radiação natural. Entretanto, a contribuição da série do $235 \mathrm{U}$ na dose total é muito baixa, dessa maneira essa série não é levada em consideração na determinação de dose (GONZÁLEZ-CHORNET; GONZÁLESLABAJO, 2004).

De todas as formas de contaminação radioativa, a mais insalubre, do ponto de vista da população como um todo, é a relacionada com a presença de átomos de ${ }^{222} \mathrm{Rn}$ e seus compostos, chamados "filhos", dispersos no ar, presentes em concentrações elevadas em alguns locais do Brasil. Nesse sentido, esse trabalho traz as principais formas de radiação a queo ser humano está submetido, bem como suas consequências e algumas das ações para minimizar as doses efetivas de incidência.

\section{PRINCIPAIS TIPOS DE RADIAC̣ÃO}

A radioatividade pode ser definida como a propriedade que alguns elementos possuem de transformar-se espontaneamente em outros, emitindo ao mesmo tempo diversos tipos de radiação que se classificam essencialmente em: radiação alfa $(\alpha)$, radiação beta $(\beta)$ e radiação gama $(\gamma)$.

A radiação alfa $(\alpha)$ é constituída por dois prótons e dois nêutrons, sendo semelhante ao núcleo $\left({ }_{2}^{4} \mathrm{He}\right)$. As partículas alfa são partículas pesadas e de carga positiva, que provocam ionizaçóes ao longo de seu percurso. Sua trajetória é muito curta, medindo-se em micrômetros na água.

A primeira lei enunciada por Soddy em 1911 relata que:"Quando um núcleo emite uma radiação alfa, seu núcleo atômico diminui de duas unidades e seu número de massa diminui de quatro unidades".

$$
{ }_{92}^{235} U \rightarrow{ }_{2}^{4} \alpha+{ }_{90}^{231} T h
$$

Com relação ao poder de penetração de cada partícula, a radiação alfa, com sua massa de prótons e nêutrons, é barrada por uma folha de papel e no caso de irradiação de seres vivos penetra apenas na camada superficial da pele, constituída normalmente de células mortas (MAZZILLI; MÁDUAR; CAMPOS, 2012). Assim, segundo os autores, pode ser potencialmente perigosa se entrar no corpo através de uma ferida, ou se for ingerida ou inalada. Já, a radiação beta é mais penetrante: desde alguns milímetros até centímetros nos tecidos vivos, conforme a sua energia. A radiação gama, que tem a velocidade da luz, pode atravessar blocos de chumbo ou concreto.

\section{CINÉTICA E EQUILÍBRIO SECULAR DE TRANSMUTAC̄ÕES RADIOATIVAS}

A transmutação natural é o processo pelo qual núcleos instáveis se convertem em núcleos mais estáveis. A emissão natural de uma partícula alfa ou beta transforma um núcleo em um novo núcleo com o número de prótons diferente. Ou seja, representa a transmutação de um elemento em outro.A transmutação artificial é o bombardeamento de núcleos estáveis com partículas $\alpha$, prótons e nêutrons, etc., feitos em aceleradores de partículas.

O urânio e o tório são "os pais" de duas séries radioativas. Estes elementos originam-se de materiais que compóem a crosta terrestre e que passam por processos de desintegração. Quando sofrem 
desintegração, os elementos originais transformamse em outros elementos, também radioativos, denominados "filhos", até chegar ao último elemento da cadeia, já estável. O Radônio, ${ }^{222} \mathrm{Rn}$ é um gás nobre produzido diretamente pelo decaimento radioativo do elemento Rádio $\left.{ }^{226} \mathrm{Ra}\right)$, presente nas rochas, no solo e, portanto, nos materiais de construção. $\mathrm{O}{ }^{222} \mathrm{Rn}$ faz parte da cadeia do Urânio $\left({ }^{238} \mathrm{U}\right)$ e origina filhos também radioativos, que emitem partículas alfa $(\alpha)$. As séries radioativas naturais do ${ }^{238} \mathrm{U},{ }^{235} \mathrm{U},{ }^{232} \mathrm{Th}$ possuem nuclídeos de propriedades físico-químicas distintas, com variações em seus períodos de meia vida. Quando o decaimento ocorre em um sistema fechado, por períodos superiores a sete meias vidas do radioisótopo de maior meia vida da respectiva série, as atividades de todos os produtos do decaimento passam a ser iguais àquela do isótopo que dá origem à série (KETCHAM, 1996). Esse fenômeno é caracterizado como equilíbrio químico secular.

No tocante à série iniciada pelo ${ }^{238} \mathrm{U}$, o produto de decaimento com maior meia vida é o ${ }^{234} U\left(\mathrm{~T}_{1 / 2}=0,245\right.$ Ma1) e o equilíbrio radioativo secular é atingido em 1,7 Ma. Para a série do Tório $\left({ }^{232} \mathrm{Th}\right)$, o produto de decaimento com maior meia vida é o ${ }^{228} \mathrm{Ra}\left(\mathrm{T}_{1 / 2}=5,75\right.$ anos) e o equilíbrio radioativo secular é atingido somente passados 40 anos. A série do ${ }^{238} \mathrm{U}$ pode ser considerada em equilíbrio após um período de 1,5 milhôes de anos; a série do ${ }^{235} \mathrm{U}$, em 190.000 anos.

Os principais isótopos de rádio, ${ }^{226} \mathrm{Ra} \mathrm{e}^{228} \mathrm{Ra}$, são gerados nas sériesradioativas naturais do Urânio e do Tório. O ${ }^{226} \mathrm{Ra}$ é um emissor alfa de meia vidarelativamente longa (1602 anos), formado a partir do decaimento radioativo sequencial decinco isótopos radioativos:

$$
\begin{aligned}
\mathrm{U}-238 & \rightarrow \mathrm{Th}-234 \\
230 & \rightarrow \mathrm{Pa}-234 \rightarrow \mathrm{Ra}-226
\end{aligned}
$$

O ${ }^{228}$ Raé um emissor beta, meia-vida 5,75 anos, formado diretamente a partir do decaimento do ${ }^{232} \mathrm{Th}$. Como metal alcalino terroso, o rádio tem características químicas análogas ao cálcio, quando incorporado concentra-se nos ossos.

Os processos geológicos ocorrem constantemente no planeta Terra, de forma que muitos desses geram fracionamentos químicos, provocando a quebra dessas

$1-\mathrm{Ma}=10^{6}$ anos. cadeias de decaimento, ocasionando desequilíbrios radioativos. Decorrido o processo de separação, caso o sistema volte a se fechar, os nuclídeos pertencentes a cada série começam novamente um processo de restauração do equilíbrio secular. A relação existente entre as atividades dos vários membros da série, entre o instante em que o sistema volta a se fechar e o instante em que a série pode, de fato, ser considerada em equilíbrio, depende das suas constantes de desintegração, das suas concentrações no instante em que o sistema se fechou e do tempo decorrido desde então (SANTOSet al, 2000).

No caso das areias de praias, estas são depósitos minerais formados a partir da erosão de rochas. Os constituintes minerais das rochas são alguns radionuclídeos naturais das séries do $\mathrm{U}$ e Th, que contribuem para a exposição à radiação na Terra (VEIGAet al, 2006).

Em certas praias brasileiras há áreas bem conhecidas pelas suas altas concentrações, que atingem cerca de 14,400 $\mathrm{nGy}^{-1}$ de dose absorvida no ar a 1,0 m (FREITAS;ALENCAR, 2004). Em certos locais do mundo, ocorrem níveis elevados de tório no solo, causando um aumento da exposição à radiação natural. Isto inclui áreas de areia monazítica presentes na costa brasileira.

\section{O DECAIMENTO DO ${ }^{238} \mathrm{U}$}

Dentre os radionuclídeos que são naturalmente radioativos encontram-se o Urânio e o Tório. $\mathrm{O}{ }^{238} \mathrm{U}$ é o primeiro elemento da cadeia de decaimento. Ele é conhecido como elemento pai, e o ${ }^{222} \mathrm{Ra}$ e ${ }^{222} \mathrm{Rn}$ são os filhos. O urânio natural na forma dos seus três isótopos ${ }^{238} \mathrm{U},{ }^{235} \mathrm{U}$ e $\left.{ }^{234} \mathrm{U}\right)$ correspondem, respectivamente, a 99,2743\%, 0,72\% e 0,0057\% da abundância do elemento(OSMOND;COWART, 1976). Dentre os radionuclídeos descendentes do ${ }^{238} \mathrm{U}$ destaca-se o ${ }^{226} \mathrm{Ra}$, que possui uma meia-vida de 1600 anos e que por emissão alfa forma o ${ }^{222} \mathrm{Rn}$, cujo tempo demeiavida é de 3,82 dias. As séries do ${ }^{235} \mathrm{U}$ e o do ${ }^{234} \mathrm{U}$ não possuem uma contribuição significativa no estudo de dose, uma vez que não há descendentes de destaque. $\mathrm{O}$ gás ${ }^{222} \mathrm{Rn}$ também produz filhos, elementos radioativos, ao sofrer decaimento, sendo estes: polônio $\left({ }^{218} \mathrm{Po}\right)$, chumbo $\left({ }^{214} \mathrm{~Pb}\right)$, bismuto $\left({ }^{214} \mathrm{Bi}\right)$, polônio $\left({ }^{214} \mathrm{Po}\right)$, 


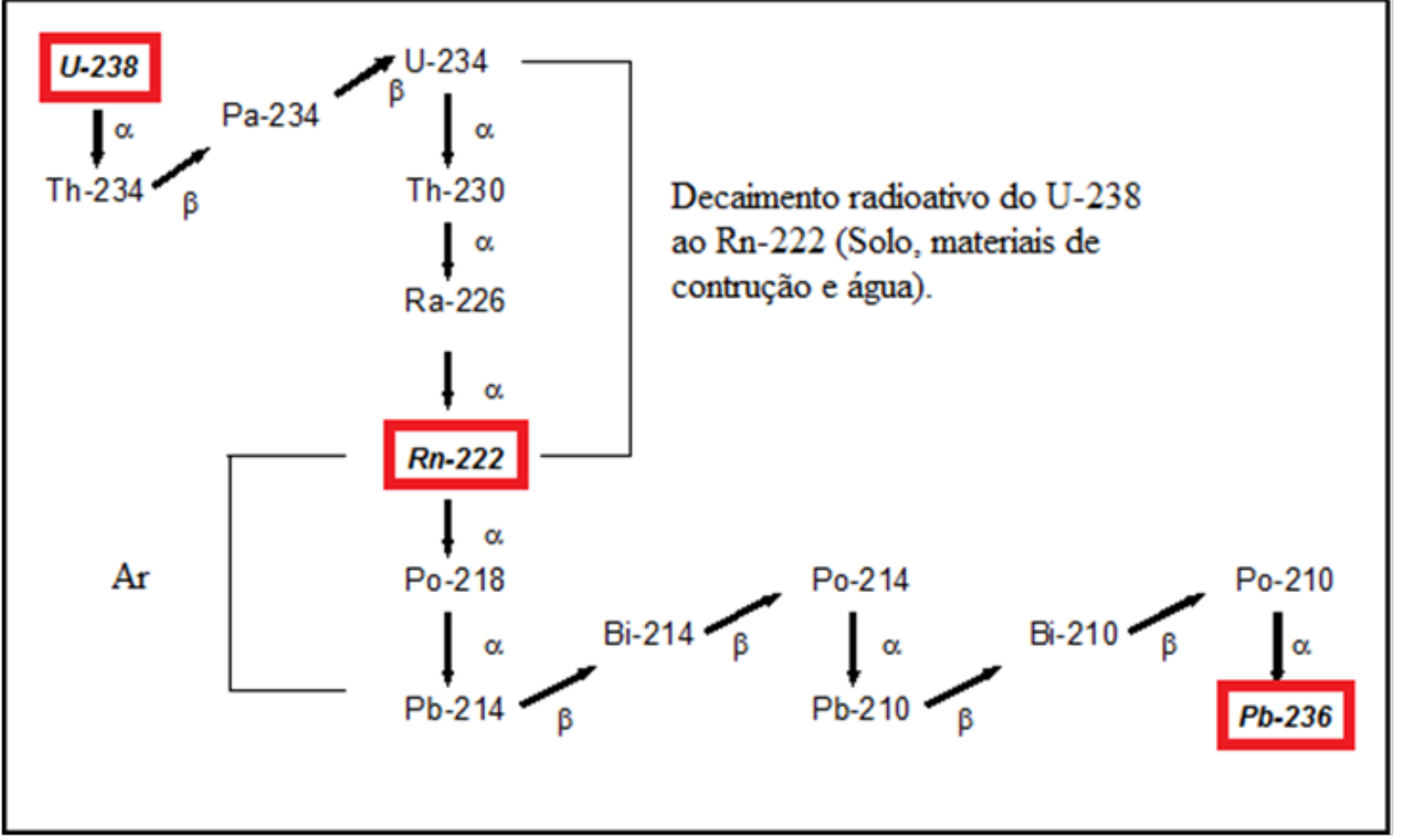

Figura 1 - Série radioativa do U-238(ARAMBURU; BISBAL, 1994)

chumbo $\left({ }^{210} \mathrm{~Pb}\right)$, bismuto $\left({ }^{210} \mathrm{Bi}\right)$, polônio $\left({ }^{210} \mathrm{Po}\right)$ e por fim o chumbo $\left({ }^{206} \mathrm{~Pb}\right)$. O ${ }^{206} \mathrm{~Pb}$ é elemento estável da cadeia do urânio, ou seja, não sofre mais decaimento radioativo (ARAMBURU; BISBAL, 1994).

$\mathrm{Na}$ Figura 1 é apresentada a série radioativa do ${ }^{238} \mathrm{U}$, bem como tipos de radioatividade beta $(\beta)$ e alfa $(\alpha)$ envolvidas no decaimento (figura 1).

\section{O DECAIMENTO DO TH}

O tório é amplamente distribuído no ambiente $\mathrm{e}$ ocorre em baixa concentração na água, solo, rochas, plantas e animais. O principal isótopo radioativo do tório é o ${ }^{232} \mathrm{Th}$, com abundância de $100 \%$ do tório natural, uma vez que os demais isotópos possuem meias-vidas curtas em comparação à esse isótopo. $\mathrm{Na}$ série de decaimento radioativa é destacada a formação do ${ }^{220} \mathrm{Rn}$, também chamado torônio, com meia-vida de 55 segundos (SALIM, 2013).

\section{O DECAIMENTO DO RA E A FORMAC̣ÃO DO ${ }^{222} \mathrm{RN}$}

O comportamento geoquímico do rádio é considerado por possuir isótopos com elevada solubilidade e meia-vida apreciável, tanto na série do
${ }^{238} \mathrm{U}\left({ }^{226} \mathrm{Ra}, \mathrm{T} 1 / 2=1620\right.$ anos $)$ e ${ }^{235} \mathrm{U}\left({ }^{223} \mathrm{Ra}, \mathrm{T} 1 / 2\right.$ $=11,68$ dias $)$ como na do ${ }^{232} \mathrm{Th}\left({ }^{228} \mathrm{Ra}, \mathrm{T} 1 / 2=6,7\right.$ anos $\mathrm{e}^{224} \mathrm{Ra}, \mathrm{T} 1 / 2=3,64$ dias). Portanto, sua mobilidade poderá ser uma fonte de desequilíbrio nas séries do ${ }^{238} \mathrm{U}$ e ${ }^{232} \mathrm{Th}$. Sua mobilização se dá, em grande parte, nas águas subterrâneas, particularmente naquelas com alta salinidade. Os radioisótopos ${ }^{226} \mathrm{Ra}$ e ${ }^{228} \mathrm{Ra}$ são emissores de radiação alfa, beta e gama.

$\mathrm{O}{ }^{222} \mathrm{Rn}$ é um gás nobre, inerte e de fácil difusão. Pode ser encontrado em ambientes de convívio humano graças ao urânio presente no solo e nos materiais de construção que contêm substâncias retiradas do solo para sua produção. O gás ${ }^{222} \mathrm{Rn}$ é originado pelo decaimento radioativo do elemento ${ }^{226} \mathrm{Ra}$, que perde dois prótons e dois nêutrons. Esse é um processo espontâneo onde o elemento que decai tende a se estabilizar, rompendo sua estrutura para gerar outro elemento, naturalmente. $\mathrm{O}^{222} \mathrm{Rn}$ também sofre decaimento radioativo, liberando uma partícula alfa e formando o elemento ${ }^{218}$ Po. E, por ser um gás nobre, possui mobilidade e não reage quimicamente com outros elementos a temperaturas normais.

De todas as formas de contaminação radioativa, a mais insalubre, do ponto de vista da populaçáo como 
um todo, é a relacionada com a presença de átomos de ${ }^{222} \mathrm{Rn}$ e seus filhos dispersos no ar. Estes são isótopos de elementos químicos que têm facilidade de estabelecer ligaçôes químicas. Os possíveis danos causados à saúde não são primariamente devidos ao radônio, pois ao ser inalado, este não fica retido no sistema respiratório por ser um gás nobre, sendo expirado ao ar. No entanto, seus filhos ligam-se a aerossóis em suspensão no ar, podendo ser inalados e posteriormente depositados no aparelho respiratório dos seres humanos, e ao decair expóem os tecidos à radiação alfa, possibilitando o desenvolvimento de células cancerígenas (câncer pulmonar), dependendo da dose de radioatividade recebida (KHAN, 2000).

Desde a década de 80, estuda-se a contaminação ambiental por radônio e filhos (CONSELHO NACIONAL DE RADIOPROSPECÇÃO NCRP, 1988; NAZAROFF; NERO JR, 1988; NEUBERGER, 1991). Esses estudos apontam que cerca de 10.000 casos de câncer do aparelho respiratório a cada ano, nos Estados Unidos, devem-se à dose recebida pelas pessoas em suas casas ou trabalho (COHEN, 1992). Essa estimativa coloca esse tipo de contaminação em primeiro lugar, em termos de insalubridade, excedendo estimativas correspondentes a outras fontes de radioatividade natural (como raios cósmicos e presença de outros elementos radioativos na crosta terrestre e atmosfera), como também artificial (MARMIER, 1971; NEMAN, 2000), incluindo, neste último caso, a contaminação por dose decorrente da atividade de usinas nucleares (que é cerca de 10.000 vezes menor que a correspondente à inalação de ${ }^{222} \mathrm{Rn}$ e filhos, de acidentes e teste nucleares; e devido ao uso de radioatividade na medicina (raios-X, por exemplo) (EINSENBUD; PASHOA, 1989).

No ano de 1955, o Public Health Service (EUA) baseado em estatísticas disponíveis sobre a incidência de câncer pulmonar em mineiros estabeleceu o limite máximo de exposição a filhos de ${ }^{222} \mathrm{Rn}$ como sendo $1,3 \times 10^{5} \mathrm{Mev}$ de energia potencial alfa para cada litro de ar ambiental. E para o público em geral adotou o equivalente a 1 pci2/Lde ${ }^{222} \mathrm{Rn}$ em equilíbrio de atividade com seus filhos. Também no ano de 1955 foram realizadas experiências com ratos que foram

2 - PCI $=$ Poder calorífico inferior expostos a uma atmosfera de ${ }^{222} \mathrm{Rn}$ e filhos e outra atmosfera contendo apenas ${ }^{222} \mathrm{Rn}$. Verificou-se que a radiação $\alpha$ (que é emitida pelos filhos do ${ }^{222} \mathrm{Rn}$ ) nos pulmóes dos ratos era maior apenas naqueles que ficaram expostos à atmosfera que continha filhos do ${ }^{222} \mathrm{Rn}$. Entre 1953 e 1954 foi reportada uma série de experimentos com ratos, cães e humanos que confirmaram que a principal parcela da dose se deve aos átomos e filhos do ${ }^{222} \mathrm{Rn}$ (CHAMBERLAIN; DYSON, 1956).

Uma das vias através das quais os radionuclídeos naturais, principalmente ${ }^{226} \mathrm{Ra}$ e ${ }^{222} \mathrm{Rn}$, podem ser transferidos ao homem é a água. Devido a isso, a determinação destes radioisótopos na água utilizada para consumo doméstico é de importância primordial para prevenir algum dano à saúde associada à sua ingestáo (BOMBEN et al, 1996).

\section{$0{ }^{222}$ RN E OS MATERIAIS DE CONSTRUC̣ÃO}

Os materiais de construção são comumente derivados de materiais naturais como areia, argila, cal e pedra, os quais contêm traços de urânio, rádio, tório entre outros. A liberação de radônio por esses materiais contribui para a exposição do indivíduo ao radônio e seus produtos de decaimento (RIO DOCE, 1997). O ${ }^{222} \mathrm{Rn}$ emana do subsolo através de microfissuras abertas pelas correntes subterrâneas de água e falhas geológicas. Ele se encontra em zonas graníticas (solos derivados do granito), e se concentra em residências, principalmente as deficientemente ventiladas (em especial poróes) ou que fazem uso constante de aparelhos de ar condicionado. Uma vez que o gás penetra no edifício, por meio do solo ou fluindo de materiais utilizados em sua construção, muito dificilmente é retirado. A vida média do ${ }^{222} \mathrm{Rn}$ é de 3,8 dias, espaço de tempo durante o qual decompóe-se, originando o Polônio. Dependendo do tipo do solo, do terreno e dos materiais empregados na construção, os níveis de radiação podem alcançar cotas elevadas (BUENO, 1992).

$\mathrm{Na}$ construção de casas, dependendo do tipo de decoração interna utilizada nas paredes para revestir os materiais de construção, pode-se diminuir ou aumentar a emanação do gás radônio (ABU-JARAD, 1988). 
De acordo com Yu (1993), um parâmetro muito importante a ser considerado no estudo da emanaçáo do ${ }^{222} \mathrm{Rn}$ no ambiente, é o tipo de revestimento empregado na construção. Materiais como madeira e ladrilho, desprendem relativamente pouco ${ }^{222} \mathrm{Rn}$, já, granito é muito mais radioativo. Bueno (1992) relata que o cimento empregado nos materiais contém em sua composição produtos como o silicato de cálcio que é um subproduto altamente radioativo no tratamento do mineral de fosfato. E ainda, a cerâmica, a olaria e seus vitrificados podem conter pequenas quantidades de tório e urânio, dependendo da origem da argila. O mesmo autor cita que subprodutos como o ferro aluminato de cálcio e o carbonato de cálcio são também produtos altamente radioativos.

Devido a esses problemas, pesquisas têm sido realizadas a fim de tentar diminuir o teor de radioatividade no ambiente. Pode-se citar como exemplo, o desenvolvimento de um concreto leve (Lightweight concrete), onde na sua composição não há mais o granito, que é muito radioativo e é a fonte principal de ${ }^{222} \mathrm{Rn}$ no cimento.

\section{IMPLICAC̣ÕES DE URGÊNCIA-DOSIMÉTRICAS DA RADIOATIVIDADE}

Dentre todas as fontes de radiação artificial, a maior e uma das mais perigosas é a de origem médica. São as exposiçóes radiológicas e os medicamentos radioativos para o tratamento de câncer, por exemplo. E ainda, dados de países industrializados indicam que são realizados de 300 a 900 exames para diagnóstico por ano para cada 1000 habitantes (excluindo os realizados em clínicas dentárias e estudos radiográficos populacionais). Entretanto, a frequência de tais exames tem decaído nos países industrializados como Suécia, Reino Unido e Estados Unidos. Mesmo assim, em diversos outros países, aproximadamente um terço da população continua sendo examinada anualmente de forma massiva (MAZZILLI e al, 2012).

Quando se fala em concentração de radiação em alguns locais específicos do Brasil, na região de Poços de Caldas, Minas Gerais, por exemplo, existe uma colina conhecida como Morro do Ferro. Nesse local, os níveis de radiação assumem valores da ordem de $250 \mathrm{mSv} / \mathrm{ano}$. Este lugar não é habitado. Por outro lado, na cidade de Guarapari, no Espírito Santo, onde vivem cerca de 12.000 habitantes e recebe até 30.000 visitantes durante as férias, são encontrados níveis da ordem de $175 \mathrm{mSv} / \mathrm{ano}$, em algumas praias cujas areias são ricas em tório. Os níveis normalmente observados nas casas da regiáo variam de 8 a $15 \mathrm{mSv} /$ ano (MAZZILLI et al, 2012).

Assim, é possível verificar que dependendo do local habitado da Terra, as pessoas podem estar em maior ou menor contato com radionuclídeos, como os habitantes que vivem no extremo setentrional do hemisfério norte e cuja dieta alimentar baseia-se na carne de rena. Essa carne apresenta concentraçóes elevadas de radionuclídeos, em particular o ${ }^{210} \mathrm{Po}$. Esse fato pode ser explicado porque no inverno, as renas se alimentam de líquens que acumulam muito ${ }^{210}$ Po. Esse moradores acabam recebendo uma dose 35 vezes maior do que os valores normais. Já no oeste da Austrália, as pessoas recebem doses 75 vezes superiores aos valores normais em virtude do fato de consumirem carne de ovinos e cangurus, que crescem nessa região rica em Urânio. (MAZZILLIet al, 2012).

No caso do gás radônio, embora as medidas se concentrem no isótopo ${ }^{222} \mathrm{Rn}$, pelo fato de sua meia vida ser de 3,8 dias, os malefícios causados pela inalação do gás são devidos principalmente aos descendentes de vida curta do ${ }^{222} \mathrm{Rn}$. Segundo Porstendörfer (1993) e Fior (2008), não é o ${ }^{222} \mathrm{Rn}$ e, sim, seus produtos de decaimento de vida curta os principais responsáveis pela dose de radiaçáo natural recebida pela população. Assim, a difusão relacionada à adsorção aos aerossóis são fatores que influenciam de forma direta as medidas da concentração de radônio em ambientes externos e internos. Com relação aos efeitos nocivos à saúde humana estudos já indicaram que o ${ }^{222} \mathrm{Rn}$ é classificado como um carcinógeno classe I pela Agência Nacional de Pesquisa em Câncer (IARC, 1986). Esses efeitos podem ser físicos, químicos e biológicos (IPEN, 2014): os efeitos físicos são absorção de energia, excitação, ionização e quebra das ligações químicas; os efeitos químicos são mobilização e neutralização dos íons e radicais livres, restauração do equilíbrio químico, formação de novas substâncias; os efeitos biológicos são aberração cromossomial, alteração no metabolismo local e morte celular. 


\section{AC̣ÕES DE PREVENC̣ÃO À RADIAC̣Ão}

Um parâmetro a ser considerado diz respeito ao tipo de revestimento empregado nas edificações. A utilização de papéis de parede e materiais cerâmicos pode diminuir a concentração do gás ${ }^{222} \mathrm{Rn}$, por exemplo (YU, 1993).

Em residências analisadas na cidade de Campinas, de acordo com Gamarra (1998), todas as atividades medidas ficaram acima dos valores médios naquelas sem pintura, bem como nas residências cujas paredes foram "pintadas" apenas com selador (produto à base de PVC que antecede a tinta sobre o reboco com função de impermeabilizante) e nas residências onde a parede recebeu apenas cal. Da mesma forma aconteceu com as residências que apresentavam cimento queimado como piso.

No mesmo estudo, evidenciou-se que em apartamentos, as atividades eram da ordem de $40 \%$ menores do que a das casas, fato que pode ser atribuído à sua maior distância em relaçáo ao solo. Ora, por ser um gás pesado, quanto mais longe do solo, menor a concentração do gás radônio (CORRÊA, 2011). Todavia, é preciso também investigar se a baixa atividade observada nesse local se deve à sua maior distância do solo ou devido à quantidade reduzida de matéria (por unidade de volume de ar) que envolve esses ambientes (uso de finas paredes feitas com tijolos baianos, por exemplo).

Por meio do revestimento de pisos e paredes, podem-se reduzir os níveis de radônio presentes nas moradias (MAZZILLIet al, 2012). O uso de papel de parede pode reduzir a emissão de radônio em até $30 \%$.

Já a dose equivalente recebida pelo trabalhador na irradiação externa é função da taxa de dose no início da irradiação e de sua variaçáo com o transcorrer do tempo de irradiação. Desta forma, existem duas maneiras para se reduzir a dose equivalente recebida pelo trabalhador, ou seja, fornecer-lhe proteção adequada. A primeira considera a variação do tempo de irradiação e a segunda considera a redução da taxa de dose, conseguida por redução da atividade da fonte, aumento da distância fonte-indivíduo ou com o uso de blindagem.

As substâncias radioativas podem encontrar-se na forma gasosa ou em suspensão no ar na forma de aerossol, e ser inalada por um trabalhador. Esta é a forma mais comum de entrada de radionuclídeos no corpo dos trabalhadores.

Ao trabalhar com substâncias radioativas na forma de pó, voláteis e gasosas deve-se ter o cuidado para evitar sua dispersão no ar e manipulá-las em locais apropriados, como capelas e caixas com luvas. Além disso, pode ser necessário o uso de máscaras ou outros equipamentos de proteção respiratória. Um controle de acesso adequado diminui o risco de contaminaçáo, pelo simples fato de manter o pessoal fora das áreas onde existe um potencial significativo de contaminação. A entrada numa área com potencial de contaminação exige o uso de roupas de proteção, as quais devem ser removidas ao deixar o local. As roupas de proteção são basicamente compostas por sapatilhas, galochas, macacóes, luvas, toucas e máscaras de proteção respiratória. Nas áreas de trabalho onde é necessário um controle mais rigoroso, o acesso é feito através de vestiários, que devem contar com, pias para lavar as mãos, recipientes para recolher as roupas de proteção utilizadas na área, instruções para operação normal e em emergência e monitores para detectar a contaminação(LDUSP, 2016).

\section{ENSINO DE FÍSICA MODERNA: A TRANSPOSIC̣ÃO DIDÁTICA}

Existe atualmente uma preocupação no ensino das ciências no sentido de apresentá-lacomo um produto de pesquisas realizadas no decorrer do tempo e não como teorias que surgiram e estão totalmente comprovadas, acabadas. Além do que, é importante promover a transposição didática do tema radioatividade na escola, visto que é um assunto atual e de interesse da população.

Ainda, ao ser analisada a visão da maioria dos alunos, de que a Física é considerada matéria complicada, aliada ao fato do ensino dessa disciplina muitas vezes se basear numa simples memorização de fórmulas e conceitos, de forma táo abstrata e longe da realidade dos alunos, a adoção de novas pedagogias pode facilitar o aprendizado.

Se usada a Teoria de Vigotskyno caso específico da Física, pode-se desenvolver um ensino voltado para a troca de ideias entre os professores e alunos, baseado no 
diálogo, na participação coletiva, dando oportunidade aos alunos que exponham suas ideias e contribuindo, dessa forma, para a aprendizagem coletiva. Em uma aula experimental, por exemplo, alunos mais experientes podem auxiliar alunos pouco familiarizados com a Física, em uma constante troca de conhecimentos. Nessa vertente, o uso de Objetos Educacionais em sala de aula pode contribuir para um ensino mais dinâmico, divertido e participativo, especialmente no tocante à Física Moderna (CAVALCANTI, 2005).

Nesse sentido, é apresentadoum Objeto Educacional (OE) que vem sendo desenvolvido para o ensino de radioatividade, Figura 2:

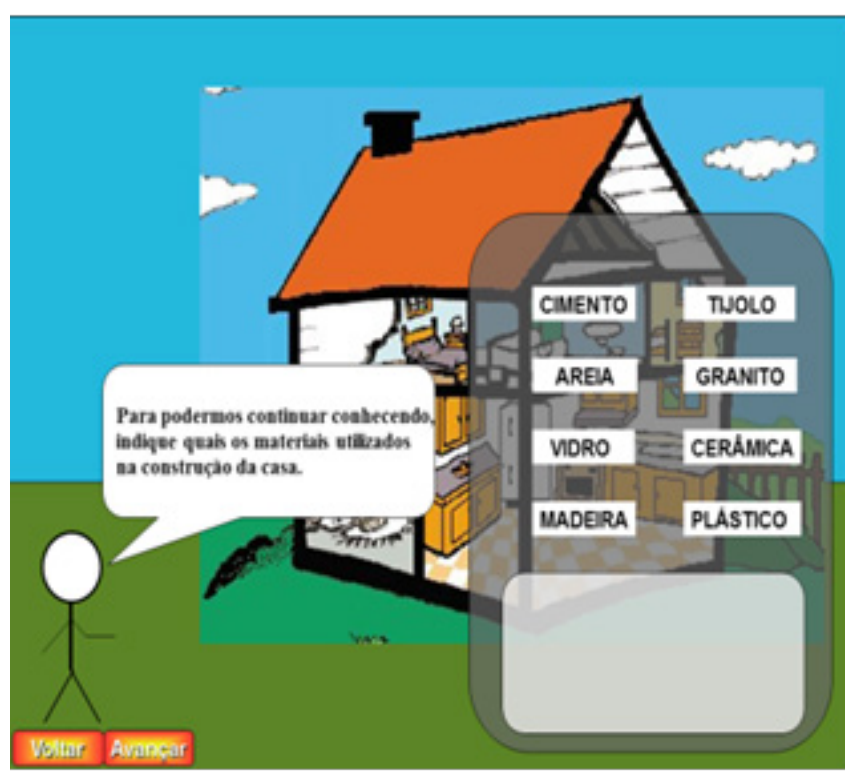

Figura 2. Telas do Objeto Educacional Radioatividade. Fonte: Autor

Com cunho interativo, este $\mathrm{OE}$ faz perguntas ao estudante ao longo das atividades e explanaçóes, e o induz a pesquisar, com posteriores correçôes. Para passar à fase seguinte, o usuário precisa acertar a resposta anterior.

Como supracitado, um objetivo muito importante inserido nesta pesquisa é realizar a transposição didática entre os estudos realizados na universidade e a escola, além de contribuir com uma área da Física, como é o caso do conhecimento dos isótopos radiativos e as doses de radiação recebidas pela população. Dessa forma, após a apresentação do conteúdo teórico por parte do docente, a utilização deste e de outros OEpode contribuir muito na fixação do conhecimento de conteúdos da Física. Cabe destacar o papel do Banco Internacional de Objetos Educacionais - BIOE como repositório e fonte de pesquisa em diversas áreas do conhecimento.

\section{CONCLUSÕES}

Uma das principais preocupações, sobre a exposição à radiação, é o potencial risco à vida da célula. Se uma radiação ionizantepenetrar uma célula viva, ela pode ionizar os átomos que a compóem. Já que um átomo ionizado é quimicamente diferente de um átomo eletricamente neutro, isto pode causar problemas dentro da célula viva. Diversas complicações podem surgir se medidas corretivas não forem tomadas rapidamente. Em casos de danos mais sérios, a célula poderá morrer. Também é possível que os danos alterem as funçôes da célula, criando, em alguns casos, réplicas inexatas de si mesma.

Depois de adotadas as medidas de recuperação em situaçóes de urgência-dosimétrica, a área deve ser monitorada para que se tenha a certeza de que as providências tomadas foram eficazes. Para a aplicação das medidas de controle necessárias deve ser usado o menor número de trabalhadores possível e estabelecer um procedimento de tal forma que as doses recebidas sejam as menores possíveis, ou seja, elas devem ser otimizadas.

Estudos constantes de dosimetria ambiental, principalmente em regióes sabidamente radioativas, fazem-se importantes como prevenção contra contaminaçóes em caso de concentraçóes elevadas de radionuclídeos, bem como monitoramento para geração de estudos e relatórios científicos.

Aradioatividadeestásendoabordadagradativamente com a produção de Objetos Educacionais que tem como objetivo garantir à população esclarecimentos sucintos e de fácil compreensão sobre assuntos tidos como de difícil compreensão. Objetiva-se fornecer alternativas ao professor do ensino básico na elaboração de suas aulas, contribuindo no processo de ensino-aprendizagem e na melhoria do ensino na área de Ciências Exatas.

\section{REFERÊNCIAS}

ABU-JARAD, F. A. Application of nuclear track detectors for radon related measurements. Nuclear Tracks Radiation Measurement, v. 15, pp. 525-534, 1988.

ARAMBURU,X.O.; BISBAL, J. J. Radiacionesionizantes: 
utilización y riesgos. Barcelona: Edicions UPC, 1994. BOMBEN, A. M.;EQUILLOR, H. E.; OLIVEIRA, A. A.226Ra and natural uranium in Argentinian bottled mineral waters. Radiation Protection Dosimetry, vol.67(3), p 221-224, 1996. BRASIL. Ministério da Ciência e Tecnologia. IPEN - Instituto de Pesquisas Energéticas e Nucleares. Sáo Paulo, Cidade Universitária. Disponível em: <http://www.ipen.br/sitio/?idm=268 >. Acesso em: 11 set. 2014.

BUENO, M.O grande livro da casa saudável. São Paulo: Roca,279p.1992.

CAVALCANTI, L. S. Cotidiano, mediação pedagógica e formaçáo de conceitos: uma contribuiçáo de Vygotsky ao ensino de geografia. Cad.CEDES, vol.25 no.66, Campinas May/Aug, 2005.

CHAMBERLAIN, A. C.;DYSON, E. D.The dose to the trackea and bronchi from the decay products of radon and thoron.British Journal of Radiology, v. XXIX, n.342, p.317-325, 1956.

COHEN, B. L. Compilation and integration of studies of radon levels in U. S homes by states nadcouties. Critical Rev. Environmental Control, v.23, p.243-364, 1992.

CORRÊA, J. N. Avaliaçáo dos níveis da concentraçáo de radônio em ambientes e águas de poços no estado do Paraná. 2011. 113f. Tese (Doutorado em Engenharia Biomédica) Programa de Pós-graduação em Engenharia Elétrica e Informática Industrial, Universidade Tecnológica Federal do Paraná, 2011.

EISENBUD, M.; PASHOA, A.S. Environmental radioactivity. Nuclear Instruments and Methods in Physics Research, A280, p.470-482, 1989.

FIOR, L. Análise da concentraçáo de radônio proveniente dos materiais de construçáo. 148f. Dissertação (Mestrado em Engenharia Mecânica e de Materiais) - Programa de Pósgraduação em Engenharia Mecânica e de Materiais, Universidade Tecnológica Federal Paraná. Curitiba, 2008.

FREITAS, A. C.; ALENCAR, A.S. Gamma dose rates and distribution of natural radionuclides in sand beaches - Ilha Grande, Southeastern Brazil.Journalof Environmental Radioactivity, v.75, n.2, p.211-223, 2004.

GAMARA, A. R. Z. Caracterização do CR-39 como espectrômetro alfa. 1998. 146f. Tese (Doutorado em Ciências) - Programa de Pós-graduação em Ciências - Instituto de Física GlebWataghin, Universidade Estadual de Campinas. Campinas, 1998.

GONZÁLEZ-CHORNET, G.E.; GONZÁLEZ-LABAJO, J. Natural radioactivity in beach sands from Doñana National Park and Mazagón (Spain).Radiation Protection Dosimetry,v.112, n.2, p.307-310, 2004.

IARC - International Agency for Research on Cancer. Monographs on the evaluation of carcinogenic risk to humans: tobacco smoking. v.38. Lyon: IARC, 1986.

ICRU - International Commission on Radiation Units and Measurements.Fundamental quantities and units for ionizing radiation, Report 60, Bethesda, Maryland, USA, 1998.

KHAN, A. J. A study of indoorradon levels in Indian dwellings, influencing factors and lung cancer risks. Radiation Measurements.v.32, p.87-92, 2000.
KETCHAM, R. A.An improved method for determination of heat production with gamma-ray scintillation spectrometry. Chemical Geology.v.130, p.175-194, 1996.

LABORATÓRIO DE DOSIMETRIA DA UNIVERSIDADE DE SÃO PAULO (LDUSP) - USP. Disponível em: <http://www. dfn.if.usp.br/pesquisa/aplicada/dosimetria/id111.htm $>$ Acesso em: 07 jan. 2016.

MARMIER, P.;SHELDON, E. Physics of nuclei and particles,v.I. 2.ed.Academic Press, 1971.

MAZZILLI, B. P.; MÁDUAR, M. F.; CAMPOS, M. P. D. Radioatividade no meio ambiente e avaliaçáo de impacto radiológico ambiental. São Paulo: Instituto de Pesquisas Energéticas e Nucleares, Universidade de São Paulo, 2012. [Apostila de aula].

NCRP.National Council on Radiation Protection and Measuremnts.Measurements of Radon Daughters in Air.New York: NCRP Publications, 1988.Report 97.

NAZAROFF, W. W.; NERO JR., A. V. Radon and its decay product in indoor air.New York: J. Wiley, 1988.

NEMAN,R.S..Medida da contaminaçáo radioativa do ar ambiental por Radônio-222 e filhos em residências de Campinas - SP. 2000. 90f. Dissertação (Mestrado em Ciências) - Instituto de Física GlebWataghin, Universidade Estadual de Campinas. Campinas, 2000.

NEUBERGER, J. Residential radon exposure and lung cancer: an overview of published studies.Cancer Detect.Prev.v.15, p.435-443, 1991.

OSMOND, J. K.; COWART, J. B.The theory and uses of natural uranium isotopic variations in hydrology. Atomic Energy Review, 14: 621-679, 1976.

PÖRSTENDORFER, J. Properties and behaviour of radon and thoron and their decay products in the air. In:INTERNATIONAL SYMPOSIUM ON THE NATURAL RADIATION ENVIRONMENT. Proceedings...Commision of the European Communities, 1993.

RIO DOCE, A. P. C. Determinaçáo da taxa de exalaçáo de Rn-222 em materiais de construçáo. 1997. Dissertação Universidade Federal do Rio de Janeiro, UFRJ-COPPE, 1997.

SALIM, L. A. Uso do Rad7 para a caracterizaçáo do torônio em águas de estâncias hidrominerais.109 f. Dissertação - (mestrado) - Universidade Estadual Paulista, Instituto de Geociências e Ciências Exatas, 2013.

SANTOS, R. N.; MARQUES, L. S.; BRENHA-RIBEIRO, F. Estudo do equilíbrio radioativo das séries do ${ }^{238} \mathrm{U}$ e ${ }^{232} \mathrm{Th}$ em rochas vulcânicas das ilhas da Trindade e de Martin Vaz. Geochimica Brasiliensis.v.14, n.1, p.135-153, 2000.

VEIGA, R.; SANCHES, N.; ANJOS, R.M.; MACARIO, K.; BASTOS, J. IGUATEMY, M.; AGUIAR, J. G.; SANTOS, A.M.A.; MOSQUERA, B.; CARVALHO, C.; BAPTISTA FILHO, M.; UMISEDO, N.K. Measurement of natural radioactivity in Brazilian beach sands. Radiation Measurements, 41- 189-196, 2006.

YU, K. N. The effects of typical covering materials on the radon exhalation rate from concrete surfaces. Radiation Protection Dosimetry, v.48, n.4, p.367-370, 1993. 